\title{
Teknoloji ve Politikanın Kesişimselliğinde Yeni Mecra Sanatı ve Toplumsal Durum
}

\section{Gökçen Ertuğrul}

Muğla Sıtkı Koçman Üniversitesi Edebiyat Fakültesi

gokcenertugrul@gmail.com

Öz

Bu makale, teknoloji, sanat ve toplumsal durumlar arasındaki ilișkiyi sorunsallaștırarak, dijital kapitalist koșullarda yeni sanatsal mevzilerin ortaya çıkmakta olduğu yolları incelemeyi amaçlamaktadır. Postfordist kontrol toplumu, dijital teknolojilerle ișlemektedir ve bu, kod etrafında eklemlenen bio-iktidar mekanizmaları üretmiștir. Toplumsal ilișkilerin ağ yapısı içerisinde örgütlendiği dijital kültür koșullarında, üretim tarzı ve sanat arasındaki kökensel bağın dijital dolayımıyla yeni tezahürlerinin sorușturulması, failliğin yeni biçimlerinin anlașılması açısından önemlidir. Bu çalıșma, teknolojiyle, sistemin normundan sapan, sanatsal ilișkilenme biçimlerine odaklanarak estetik ve politika arasındaki ilișkinin nasıl eklemlendiğini incelemeyi amaçlamaktadır. Bu, aynı zamanda, yeni toplumsal koșullarda belirmekte olan yeni direniș pratiklerini kavramaya çalıșmak anlamına da gelmektedir.

Anahtar Kelimeler: Kontrol toplumları, dijital kültür, yeni mecra sanatı, teknoloji, dijital șiir

Makale geliș tarihi: 29.03.2016 • Makale kabul tarihi: 22.04.2016.

http://ilefdergisi.org/2016/3/1/

ilef dergisi · (c) 2016 · 3(1) • bahar/spring: 7-29 


\section{New Media Art at the Intersection between Technology and Politics and the Social Conditions}

\section{Gökçen Ertuğrul}

Muğla Sıtkı Koçman University Faculty of Letters and Humanities

gokcenertugrul@gmail.com

\section{Abstract}

This article, by problematising the relationship between technology, art and the social conditions, aims to examine the ways through which new artistic positions are emerging within digital capitalist conditions. The postfordist society of control works with digital technologies and this has produced mechanisms of bio-power which are articulated around the code. Under the conditions of digital culture in which social relations are organised around the network structure, an examination of the manifestations of the connection between mode of production and art through the digital is important for understanding the new modes of agency. This study, by focusing on the artistic modes of relating with technology that deviate from the norm of the system, aims to scrutinize how the relation between aesthetics and politics is articulated under digital conditions. This also amounts to an understanding of the new practices of resistance emerging under the new social conditions.

Keywords: The societies of control, digital culture, new media art, technology, digital poetry 
1970'lerden itibaren ${ }^{1}$ postfordist, postmodern, kontrol toplumlarına geçiş, 1990'lar sonrası, görselliğin, işitselliğin, metinselliğin ve dokunurluğun yeni formlarının oluşturduğu "siberkültürel (ya da teknokültürrel) dönemeç" ile buluşur. Bu süreçte, sanatsal pratikler ve teknoloji arasındaki kökensel bağ, sadece değişen malzemenin sanatı nasıl dönüştürdüğüne dair bir tartışmayı değil, aynı zamanda eleştirel sanatın, yeni akışkan teknolojilerle, bu teknolojilerin gücünü yine teknolojilerin kendilerine karşı kullanarak, nasıl imkanlar yaratabileceği ve bu yeni ekoloji koşullarında hangi etik ve politik konumlanmalar eklemleyebileceğine dair soruşturmaları öne çıkarmıştır. Sanatsal pratikler ve estetik deneyim, endüstriyel dönemin ağır somut makinalarının aksine, çoğu görünmez olan bu teknolojilerin ontolojilerini sorgulamanın ve politik meydan okumaların bir arenası haline gelmektedir. Dijital olanın sanallık bağlamında kavramsallaştırıldığı formülasyonlar artık geride kalmıştır. Bu koşullarda, sanatsal deneyler, dijital olanın imkânlarını ve sınırlarını keşfe çıkmaktadır ve bu haliyle de estetik tartışmalar etik ve politik pratiklere dönmektedir. Bu makale, mecrayla deneylere girişen bu pratiklerin, politik olanı nasıl eklemlemeye çalıştı̆̆ına ve hangi yeni direniş kiplikleri ortaya ç1karmakta olduğuna odaklanacaktır. 


\section{Dijital Kültür ve Yeni Toplumsal Durum}

Ortaya çıkışı, 1950’lerdeki soğuk savaş, nükleer tehlike, merkezi askeri kumanda ve kontrol sistemlerinin zafiyetine çözüm arama temelindeki askeri ilgilerle bağıntılı olan İnternet, ${ }^{2}$ bütün toplumsal ilişkileri dijital ağlar etrafında örgütleyen "ağ toplumu"3 olarak kavramsallaştırılan yeni bir toplumsal durumun belirişine ve postfordist esnek üretim koşullarında "dijital kapitalizm" $\mathrm{e}^{4}$ götüren bir politik ekonomik geçişe de neden oldu. Artık dijital sistemler ve siberuzamlar, hem artı değer üretiminin hem de idari-bürokratik yönetimselliğin iktidar mekanizmalarının temel mecralarıdır. Ağlar artık var olan toplumsal düzeni açı̆̆a çıkarmak için kullanılan bir yöntem değil, bizatihi postendüstriyel kapitalizmin bir aygıtı, yeni bir toplumsal durumun kendisi ve bu durumun egemen iktidar biçimidir. ${ }^{5}$ Michael Hardt, Antonio Negri ve Paolo Virno gibi autonomist hareketten gelen kuramcılar, bu ağ yapısının, Batı'daki militan ve örgütlü emekten, gelişmekte olan ülkelere kaçan sermayenin, ağlar biçimini alan iletişim, işbirliği ve duygulanım temelinde enformasyon ve hizmet üreten maddi olmayan emek etrafında yeniden mevzilenmesi ve sermayeye muhalefet eden emeğin yeni biçimleri ile beraber evrildiğini iddia ederler. $^{6}$

"Kontrol toplumu" olarak da adlandırılan bu toplumsal durumun belirişi, enformasyon sistemlerine yönelik askeri-endüstriyel ilgilerin ve sibernetik araştırmaların ortaya çıkışıyla da eşzamanlıdır.7 Onları üretmeye ve kullanmaya muktedir toplumsal biçimleri ifade ettikleri için makinalarla, dönemin sosyopolitik mantığı arasında ilişki kuran bu yaklaşıma göre, klasik dönemin mutlak iktidarları, basit makinalarla çalışırken, onu izleyen disiplin toplumları termodinamik makinalarla teçhizatlanmıştır. Bu tarihsel dönemlendirmenin son aşaması olan kontrol toplumu ise üçüncü kuşak enformasyon teknolojileri ve bilgisayarla çalışmaktadır. ${ }^{8}$ Ayrıca, kontrol toplumunda politik, teknolojik ve iktisadi olanın kesiştiği bir alan olarak Web, gözetimin, değişen tüketim pratiklerinin ve enformasyon hizmetleri, duygulanımsal emek ve iletişim pratikleri üreten maddi olmayan emeğin temel bağlantı noktası haline gelmiştir. ${ }^{9}$ Gilles Deleuze'e göre, disiplin toplumundaki aynı anda hem bireyselleştiren hem de kitleleştiren, yani bireye işaret eden imza ve kitle içindeki konuma işaret eden sayı üzerinden işleyen, iktidarın yerini, kontrol toplumlarında enformasyona erişimi işaretleyen kod almıştır. ${ }^{10}$ Kesikli enerji üreten disiplin insanıysa, yerini, yörüngede ve sürekli bir ağ içerisinde olan dalgamsı kontrol insanına bırakmıştır. Her yerde en eski sporların yerini sörfçülük almıştır. ${ }^{11}$ 
Dolayısıyla, dijital kültür, dijital kapitalizm koşullarında, artı değer üretiminin, gözetimin, "siber-proleterleşme"nin ve biyopolitik üretimlerin uzamıdır ve İnternet 2.0 ve sosyal ağlar dijital emek üretimine ve platform kullanıcılarının bedava emeğine dayanan "toplumsal fabrikalar" dır. ${ }^{12}$ Utku Özmakas'a göre, “dijital emeğe dayanan insan sermayesi zaman içerisinde yalnızca duygulanımları yönlendirmekle kalmayacak; aynı zamanda sanal vitrini canlı tutmak adına gerçekleştirilen performansların da yalnızca bu sermayeye katkı sunacak edimler olmasını getirecektir."13

Ancak, direniş pratikleri her zaman mümkündür. Şirket ile devlet iktidarından görece bağımsız, yeni iletişim alanları açmaya ve toplumsal mücadeleleri destekleyen enformasyon ve içerik sağlamaya yönelik otonom medya deneyimlerinin ${ }^{14}$ yanısıra, çok daha farklı bir muhalefet ve müdahale biçimi olan teknolojinin kendisi içerisinden alanlar açmaya çalışan sanatsal karşı hareketler de mevcuttur. Keza sanat da disiplin toplumlarına özgü kapatılmanın mekanlarını terk etmiştir ve kontrol toplumları için tehlike, artık disiplin toplumlarındaki gibi sabotaj ve entropi değil, sinyal boğma (jamming), korsanlık ve virüslerdir. ${ }^{15}$

Toplumların bilgisayarlaşması, Jean-François Lyotard'ın postmodern durumu, "büyük anlatıların ölümü" olarak ilan etmesinin temel nedenidir. Lyotard, modernitede egemen iki temel bilgi meşrulaştırım anlatısının, yani devletin, "millet" adı altında, ilerleme yolunu göstermek için "halk" üzerinde doğrudan bir güç kazandığı özgürlük anlatısına müracaat eden Fransız geleneğiyle, tinin gerçekleşmesi, yani Bildung ve spekülatif bilgi'de temellenen Alman geleneğinin hükmünü yitirdiğinden bahseder. ${ }^{16}$ Modern dönemde, sadece toplum ve bilgi arasındaki ilişkileri ifade etmekle kalmayan, ama aynı zamanda, toplumun idaresinin temel ilkesini de belirleyen bu büyük anlatıların ölümü, teknolojiyi "doğru", "adil” ve "güzel"e dair bir oyun olmaktan çıkarıp, "yeterliğe", yani kar elde etme arzusuna dayalı işlerliğe (performativity'e) ilişkin bir oyuna dönüştürmüştür. Ancak, araçsal rasyonaliteye dayanan teknoloji, yaratım ve kullanım merkezli teknokapitalizm, teknolojilerle kurulan ilişki kipliklerini kapatmaktan ve sabitlemekten uzaktır ve üretim ve teknikle kökensel bağı olan sanat, bu çatlakları keşfe çıkma deneylerine girişmektedir.

Alexander Galloway'e göre, disiplin toplumundaki panoptikonun yerini kontrol ya da iletişim toplumunda protokol almıştır. ${ }^{17}$ Ancak bu durum, bioiktidarın tam da mecrası olan ağ sisteminde [nasıl ki bioiktidar, bir "türdüzeyi bilgisi" ise (species-level knowledge) protokol da kodlanmış yaşam 
formları için bir "tür-bilgisi" (species-knowledge) biçimidir] karşıt-protokol güçleri de üretmiştir; ki bu güçler, protokol akışları içerisinde, küresel sermayenin kontrol yapılarına karşı yabancılaşmamış bir toplumsal hayat ütopyası amacına yönelirler. ${ }^{18} \mathrm{Bu}$ pratikler, protokol teknolojilerini reddetmeye değil ama protokolojik teknolojilerin yapısını rahatsız ederek protokol içerisinden “özgürleşmiş mecralar” yaratmaya yönelirler. Anlam ve mana ile hareket eden söylemden (gösterenin, insanın sesinin ve derinliğinin, bedenin yüreğinin krallığından), paternin krallığına (bedenlerin ve enformasyonun paternli duygulanımına, paternleştirici aygıt olan daktiloda cisimleşmiş makinalara ve algoritmaya) doğru olan paradigma kayması, ${ }^{19}$ aynı zamanda, Galloway'a göre, Michel Foucault'un formüle ettiği dönemleştirmeyle, mutlak toplumlardan disiplin toplumuna geçişe tekabül eder. Disiplin toplumundan kontrol toplumuna geçiş ise, bilgisayar ve sibernetik makinalara, yaygın ağlara (yani düğüm ve dağıtım merkezleri olmayan ve her bir birimin otonom ve bağlantıda olduğu sisteme) ve bürokrasiden protokol'a geçişe tekabül eder. Ancak, Galloway'e göre, İnternet'in, hem yatay hem de bu yatay mantığ1 tabakalaştıran dikey mantıkla örülmüş ikili doğasının (merkezileşen kontrol ve merkezsizleşen düzenleme) bir politik teknoloji olan protokolojik altyapısı, "yazılım-sanatı", "açık kod faaliyetleri" ve "network politikası" gibi "karşıprotokol" pratiklerine de yol vermiştir. ${ }^{20}$ Dolayısıyla tam da bu dijital mecra, günümüz toplumsal koşullarına yeni tür bir müdahalenin ve eleştirel sorgulamanın eklemlendiği bir alan olarak belirmektedir.

\section{Üretim, Teknoloji ve Sanat Arasındaki Kökensel Bağın Yeni Tezahürleri}

Sanat (İngilizce $a r t$ ), zanaata dayalı her türlü beceriyi ifade eden Latince ars ve Yunanca techne sözcüklerinden türetilmiştir. Arapça kökenli sanat sözcüğü de, sanaat/ sınaat, yani üretim için yapılan iş ve ustalık anlamına gelir ${ }^{21}$ ve üretim tarzıyla olan kökensel ilişkisinin izini taşır. Ancak, Antik Yunan ve Ortaçağ dâhil olmak üzere bu bağın en görünür olduğu alanlar (heykel, hatta resim- ki malzemesi nedeniyle ressamlar, eczacılarla aynı loncaya bağlıdırlar ve sonrasında fotoğraf), sanatlar hiyerarşisinde en altta yer alırlar ve tanınma süreçleri, örneğin zihin emeğine dayalı şiir ya da besteye kıyasla, daha sancılı olmuştur. Modernitede sanat, maddi üretim tarzı ile bağı koparılarak, yaratılmamış bir yaratıcı imgesine bürünen sanatçının, yapılmış olarak görülmeyen "eserleri" ilhamla ürettiğine inanılan bir alan haline gelir ve "yapımın izleri silinmeye" çalışılır..$^{22}$ Öte yandan, sanatın dönüştürücü potansiyeli, eğer varsa, tam da sanatın üretim tarzıyla olan bağlantı noktasında yatar. 
Walter Ong'a göre, yazı teknolojisi, "insan bilincini en çok değiştiren tekil buluş”tur ve düşüncenin yapısını değiştirir. ${ }^{23}$ Bir teknoloji olarak yazı, “olayların veya önerilen gerçeklerin soyut, dizimsel, sınıflandırıcı ve açıklayıcı bir çözümlemesini" mümkün kılar ve "kelimeleri görsel boyuta hapsederek", gözün, kulak ve söz üzerindeki egemenliğini ilan eder. ${ }^{24}$ "Konuşma dilinden yazı diline geçiş, aslında sesten görsel mekâna geçiş" demektir. ${ }^{25}$ Sözlü belleğe dayanan sözlü kültürden, yazılı ve basılı kayda geçiş, edebi ve sanatsal üretimler için de önemli dönüşümleri beraberinde getirir. Edebi ve sanatsal üretimlerdeki dönüşümlerle bellek arasındaki ilişkiler, aynı zamanda sözlü kültürün dinamiklerinin kavranmasında önemli yeni kavrayışlara da götürür. Yaratıcı şairin dil kullanma yeteneklerini yücelten saptamalar, yerini, tekniklerle bellek arasındaki ilişkileri soruşturan analizlere bırakır. Örneğin, sözlü olarak oluşturulan Homeros'un şiirleri, sözlü belleğe dayanıyor olmasından kaynaklı olarak kolay hatırlamayı mümkün kılacak heksametrik dize ölçüsüne (bir uzun iki kısa heceden oluşan altı vuruşlu dize) bağımlıydı ve şair, dize ölçüsü tutturmak için sıfatlar uydurmak zorunda kalıyordu. ${ }^{26}$ Ong, böyle bakıldığında aslında Homeros'un yoktan yaratan bir şair imajının bozulduğunu ve bir montaj işçisine dönüşüverdiğini söyler. Öte yandan, sese dayalı bellekten yazılı kayda geçiş, anlatı yerine, hatta bizatihi anlatıdan kaçınan, tipografik mekânı- kelimelerin sayfa yüzeyindeki tam yeri ve birbirleriyle olan ilişkisini- merkeze alan deneyleri mümkün kılmıştır (Ong bunun ilk örneklerinden birinin Stéphane Mallermé'nin "Un coup de dés" ("Zar Atışı") şiiri olduğunu söyler). ${ }^{27}$ Postmodernizmin başlangıcı olarak kabul edilen Dadaizm de tam da yazının bir teknoloji oluşuna yönelik bir farkındalığa dayanan montaj ve kolaj deneyleriyle uğraşmıştır; ki bu, ancak yazılı ve basılı teknolojilerin varlığında mümkün olmuştur. Dijital belleğe ${ }^{28}$ ve Hiperlinguistik olana, aynı zamanda kendisi de bir makina ve icranın (eylemin) kendisi olan yeni tür bir dile, yani kod'a (Kittler'in ifadesiyle "postmodern Babil Kulesi"29), dayalı ve mecrası siberuzam olan şimdiki sanatsal pratikler ise info-tech, info-politika ve bio-politika kesişimselliğinde yeni bir tür deneyi ortaya çıkarmaktadır. ${ }^{30}$

Mecrayı (medium) merkeze alan kuramcıların yaklaşımları, teknolojik determinizmle eleştirilseler de, insan algısı ve bilincin yapısı ile teknoloji arasındaki bağı soruşturmak açısından önemlidir. Harold İnnis, mecraları, "zamanı uzatan" ve "mekanı uzatan" olarak ikiye ayırarak, toplumsal düzen tipleri ile mecra tipleri arasında bir korelasyon kurar. İlkinin tek mümkün mecra olduğu geleneksel toplumlarda, enformasyonu saklamanın yolunun zamana karşı oldukça dayanıklı ama taşınabilir olmayan kil ya da taş mecrasına kaydedildiğini, bu toplumlarda bilginin "ebedi hakikat" olarak görüldüğünü 
ve hiyerarşik kurumsal biçimlerin egemen olduğunu söyler. ${ }^{31}$ Modern toplumlarda ise temel mecra, uzaklı̆̆ın zamansal değil mekânsal olduğu "uzakta edim" dir. Bu ikinci mecra ise bilginin zamansız ve tarih dışı bir hakikat olarak görülmediği modern topluma özgü ticari ve yönetsel yapılarla ilişkilendirilir. Dijital bellek ise insanın ne'liğini ve kimliğini sorgulamaya götüren sonuçlara götürmüştür. Dijital kültürle birlikte, tüm duyuları ve bedeni çoğaltan dijital metinsellik ile beraber, beden ve makinalar arasındaki sınırların kalktığını ve insan bedeninin ve zihninin teknolojiyle dönüştüğünü tartş̧an postinsan kavramsallaştırmaları başlamıştır. ${ }^{32}$

Marshall McLuhan ise yazılı kelimenin, modern toplumun temeli olan düşünümsel, tekil rasyonel modern insanı mümkün kıldığını iddia eder. ${ }^{33}$ Basım teknolojileri, bireyin duyu ve yetilerini dönüştürür ve söz ile eylem arasında bir ayrım ortaya çıkarır. Duyular arasındaki önceki dengeyi bozarak, içine katılmadığı hayatı bir sahne üzerine düşünür gibi düşünen gözü egemen kilar.

Öte yandan, Jonathan Crary, görme makinalarının ve güneşe saatlarce bakarak görsel deneyler yaparken görme yetilerini sakatlayan Sir David Brewster, Joseph Plateau ve Gustav Fechner gibi bilim adamlarının dışarıdaki herhangi bir referanstan arındırılmış öznel görme deneylerinin, algıyı değiştirdiğini ve egemen görme normlarından sapan soyut görme deneylerinin bir mecrası olan modernist görsel sanatların, tüketim kapitalizmini mümkün kılan bir görme rejimini ve yeni iktidar aygıtlarının inşası için hayati bir kırılmayı oluşturduğunu söyler. ${ }^{34} 17$. ve 18. yüzyılların geometrik optiğinden, 19. yüzyılda fizyolojik optiğe geçiş, aynı zamanda, görmenin, Camera Obscura' nın bedensiz ilişkiler ağından çıkartılması ve yeniden insan bedeninin içine yerleştirilmesi süreciydi. Camera Obscura, öznelliği bastırırken, Stereoskop, optik deneyimin radikal bir biçimde soyutlanmasına ve 'öznel görme' modeline dayanmaktaydı ve bu anlamda kitlesel görsel kültürde 'gerçekçi' etkiler üretmek için çok yaygın olarak kullanılan araçların ilk örneğiydi. Crary, fotoğrafın ya da dijital teknolojilerin yarattığı kırılmadan çok daha temel bir kırılmanın, bu nedenle, 19. yüzyılda, Camera Obscura' dan Stereoskop'a geçişte yaşandığını vurgulayarak, yeni görme tekniklerinin gelişiminin, öznenin disipline sokulması ve hâkim kurumsal iktidarın gereklerine göre biçimlenmesi sürecinin bir parçası olduğunu söylüyor:

İncelediğim 19. yy.'a ait optik aygıtlarda, en az panoptikonda olduğu kadar, bedenlerin uzamda düzenlenmesi, etkinliğin düzene sokulması, bireysel bedenlerin kullanılması söz konusuydu ve böylece gözlemci, katı bir biçimde tanımlanan 
görsel tüketim sistemleri içinde kodlanmış ve normalleştirilmiş oluyordu. Bunlar, dikkatin yönetilmesi, homojenliğin ve göçebelik karşıtı uygulamaların dayatılmasına yönelik olarak, 'bireyin siyasal bir kuvvet olarak indirgendiği bölmelerin ve hücrelerin' kullanılmasıyla gözlemciyi sabitleyen ve yalıtan tekniklerdi. Kitle kültürünün örgütlenmesi, toplumsal pratiğin önemsiz ya da üstyapısal bir alanında gerçekleşmiş değildir; tamamen Foucault'nun işaret ettiği aynı dönüşümler içinde yaşanmıştır. ${ }^{35}$

Öte yandan, kültürel ve sanatsal pratikler bağlamında, teknolojiyle kurulan ilişki, eşitsizliklerle, toplumsal bölünme ve iktidar mücadeleleriyle işaretlenmiştir. Pierre Bourdiue'nün 1960'larda meşruluk için mücadele eden yarı-tanınmış bir alan olarak fotoğrafçılık üzerine gerçekleştirdiği çalışma, teknolojiye atfedilen anlamın ve işlevin, toplumsal grupların yapı ve değerlerine, bu grupların toplumsal yapıdaki konumuna ve diğer grup ve pratiklerle farklılaşma stratejilerine göre nasıl değiştiğini ortaya koymuştur. ${ }^{36}$ Neyin fotoğraflanabilir olduğu, neyin sanat, neyin sadece gerçekliğin bir kaydı olduğu, dünyanın ve teknolojinin nasıl algılandığıyla bağlantılıdır. Bourdieu bu doğrultuda popüler estetik ve ethos ile estetik pratikler arasındaki temel bölünmeyi ortaya koyduktan sonra, ikincisi içerisindeki ayrımların sınıfsal kökenlerini gözler önüne serer. Popüler estetik ve ethos, fotoğrafı dünyanın "gerçek temsili" olarak görüp, fotoğrafa, fayda ve toplumsal işlevler (ailenin yaşamının ve aile tarihinin kutlanması ve ölümsüzleştirilmesi gibi) üzerinden anlam yüklerken, bu normdan sapan sanatsal pratikler bu bağı koparır. ${ }^{37}$ Sanatsal pratikler ise yine iki farklı estetik ve değerler sistemiyle bölünürler: Kendilerini teknolojiyle olan bağdan uzaklaştırarak yücenin estetiği çerçevesinde pratiği meşrulaştıran orta ve üst sınıf fotoğrafçılık kulüpleri ve teknolojinin izlerini silmek yerine fotoğrafın teknik boyutunu öne çıkaran işçi sınıfının oluşturduğu kulüpler. ${ }^{38}$ Teknolojiyi, yani fotoğrafçılığın makinaya ve kol emeğine dayanan boyutunu (örneğin, laboratuvar kısmını) öne çıkaranlarla, "bakış"1 yücelten ve yücenin estetiğine sığınan ve resim sanatını model alanlar arasındaki ayrım, tesadüfi bir ayrım değildir fakat sınıf farklılıklarının bir tezahürüdür. Bu durum, 1960'lar bağlamında, teknoloji ve sanat arasındaki paradoksun, kol emeğiyle süreklilik içinde görülen teknolojinin otomatizmi ile saf akıl/bakış ve esine dayanan yaratı arasındaki mücadele alanında nasıl ortaya çıktığını göstermesi açısından önemlidir. Dijital koşullarda, teknolojiyle işlevselliği temelinde ilişki kuran popüler ethos'tan, kapitalizmin teknolojiyle işlerliğe ve mülkiyete dayalı araçsal ilişkisinden ve yücenin estetiğinden kopan, maddi olmayan artı değeri üreten zekânın teknolojiyle yeni ilişkilenme biçimleri, yeni mecra sanatı alanında ortaya çıkmaktadır. 


\section{Dijital Yeni Mecra Sanatı}

Pramod Nayar, mobil telefonların, desktoplardaki görsellerin, Web üzerinden yayınlanan müziğin, Web telefonlarının ve SMS formatındaki metinlerin oluşturduğu yeni görsellik, işitsellik ve taktikselliklerin bir noktada birleştiği bir siberkültürel dönemeci deneyimlediğimizi söylüyor. ${ }^{39}$ Yeni mecra sanatını ise, her kullanıcının bir üretici-sanatçı olduğu ve tür sınırlarını kaldıran total bir dil deneyimi içerisinde oyun, akışkanlık, rastlantısallık ve süreksizlik içeren hipermetin (ya da digitextuality) temelinde üretilen bir pratik olarak tanımlıyor. ${ }^{40}$ Bu pratik, "seyirciyi", "voyörden katılımcıya"; metni ise "gösteriden çevre oluşa" dönüştürüyor. ${ }^{41}$ Artık sanal (virtual), somutun karşıtı olan soyutluk olarak değil, fakat gerçek etkilere ve dönüşümlere yönelik işleyen bir potansiyellik içeren "soyut-ama-gerçek" (abstract-but-real) olan olarak tanumlanmaya başlanmaktadır. ${ }^{42}$ Bu kullanım, kelimenin etimolojisiyle de haklılaştırılmaktadır. Gerçekten de "virtual" (sanal) kelimesi, her ne kadar 1959 yılında, bilgisayar bağlamında "fiziksel olarak var olmayan fakat yazılım tarafından beliren" anlamıla tasdik edilse de, kelimenin etimolojisi, kelimenin 15. yüzyıl ortalarından itibaren, "özde ya da etkide var olan ve belirli bir etki üretmeye muktedir" anlamıyla kullanıldığını göstermektedir. ${ }^{43}$ Kökene dönerek yapılan bu yeniden tanımlama, siberkültürlerin ve sibermekanın, "hardware" (elektronik)-"software" (yazllım, programlar)-“wetware” (insan) (Manuel Castells'in terminolojisini çağırırsak teknik, kullanıcı ve ekonomik) coğrafyalarının eklemlenmesinden ortaya çıkan bir ortam ve uzam olduğu ve ara yüzün de bir gerçek kültürel göstergeler sistemi olduğuna işaret eder.

Timothy Allen Jackson, dijital çağda, toplumsal, politik, ekonomik ve kültürel olarak var kalmanın hayati yollarından birinin, henüz egemen bir estetik model oluşturmamış olan yeni mecraların akışkanlığını, icat yoluyla avantaja çevirmek ve sanatı, ideolojiler içinde kopuşlar yaratarak tam da iş dünyasını ve onun yarattığı sefaleti güzelleştirmekten ziyade imha edecek bir teknik imkân olarak görmek olduğunu söylüyor. ${ }^{44}$ Estetiğin, dünyayı nasıl bildiğimizi ve duyusal analiz dolayımıla anlamı nasıl eklemlediğimizi soruşturan bir felsefe kolu olduğuna işaret eden Jackson, isimdense fiile benzeyen dinamik yeni mecraların, yeni deneyim tipleri ve sanat üretme ve tüketme biçimleri sağlayarak teknolojinin anlamını müzakere edecek yeni meydan okumalar sunduğunu ifade ediyor. ${ }^{45}$ Yeni mecralar, tıpkı hava durumu gibi gerçek, dinamik ekolojik sistemimizin bir parçasıdır; etkisi bakımından sanal olmaktan çok uzaktır; doğası itibariyle estetiktir. Bu yüzden de yeni estetik konumların rolünün, yeni medya teknolojilerinin, toplumsalı nasıl analog hayattan dijital 
hayata dönüştürdüğünü, zaman ve mekânla kurulan önceki ilişki ve gerçeklik tanımlarıyla yaşanan kopuşu sorgulamak olduğunu belirtiyor. Jackson'a göre, imparatorluk-inşası için en son karasal hudutu cisimleştiren yeni mecralar, aynı zamanda sanatsal pratikler yoluyla egemen kültürün dokusunda "yıkıcılık" alanları yaratacaktır.

Galloway, durum betimlemesinin ötesine geçerek, yeni mecra sanatını, kontrol toplumunun politik teknolojisine politik bir müdahale olarak okur. Galloway'e göre İnternet'in altında yatan protokoller, fiziksel medyayı düzenledikleri, kültürel oluşumları yonttukları ve politik kontrol uyguladıkları için nötr değillerdir. Teknik her zaman politiktir ve bilgisayar ă̆g'nın (network) mimarisi politikadır. ${ }^{46} \mathrm{Bu}$ nedenle bu ağ içerisindeki her sanatsal pratik, ta başından politik olanla angaje olmalıdır.

Galloway, protokolojik mecra olarak kavramsallaştırdığı dijital teknolojilerin ve İnternet'in devrimci eleştirisinin, biçimsel niteliklerinin bir eleştirisi olduğunu söyleyerek, baskıcı olmayan bir biçimin ve özgürleşmiş bir mecranın bu tür pratiklerden çıkacağını iddia eder. ${ }^{47}$ Hacking ve taktiksel medya ${ }^{48}$ türü tekno-altkültürler, bu tür protokolojik pratiklerin ilk biçimleridir. Taktiksel medya, Galloway'e göre, teknolojiyi reddeden değil ama onu hipertropi durumuna ittiren, bizatihi kontrol toplumunda akışları kontrol eden, netuzamı yönlendiren, ilişkileri kodlayan ve yaşam biçimlerini birbirine bağlayan bir kod dili olan Protokol içerisinde işleyen teknolojinin politik kullanımlarına dayalı tekno-direniştir. ${ }^{49} \mathrm{Bu}$ direniş, protokolojik ve mülkiyete dayalı kontrol süreçlerindeki zaafları sömürür ve protokolü bir heykel gibi yontarak "gerçek arzulara" daha uygun hale getirmeye çalışır. Örneğin, hackerlar ve virüsler, mutasyonlar, çökmeler ve viral kodlarla protokol içerisinde negatif alanlar yaratırken, siberfeminizm (ilk siberfeminist manifesto 1997'de kendilerini VNS Matrix olarak adlandıran bir grup sanatçı tarafından uluslararası bir çağdaş sanatlar sergisinde duyurulmuştur), patriyarkanın ve onun teknolojik anlamdaşı olarak gördükleri mülkiyetin zayıflatılması için, kadın bedeni ve makina arasındaki temel maddi bir aradalığı öne çıkararak, sistemde kısa süreli hatalar yaratır ve protokolü rahatsız etmeyi amaçlar. ${ }^{50}$

Yeni mecra sanatı, İnternet sanatını önceleyen modern bilgisayar teknolojilerine meydan okuyan iki temel gücün, hacking ve taktiksel medyanın, mümkün kıldığı spesifik bir politik bağlamda ortaya çıkar. ${ }^{51}$ Hacking, bütün enformasyona özgürlük talebi, bürokratik kontrole ve polis, eğitim, aile gibi kurumlara karşı bir reddiye içeren liberter bir duruşu içerirken, taktiksel medya, ilerici sol siyaset ile harekete geçer. Net sanatı ise, kavramsal bir sanat 
olarak, İnternet'in protokollerinin görünmez uzamıyla oynar; sistemdeki hataları keşfeder ve kullanır; yazılım teknolojileriyle ilgilenerek yaratıcı pratikler ortaya çıkarır. Galloway, yeni medya sanatını iki döneme ayırır: 1995-1999 yılları arasında ortaya çıkan "network sanatı" ve 2000 sonrasında ortaya çıkan "yazılım sanatı". ${ }^{52}$ Network sanatı, İnternet'in kavramsal kullanımlarına dayanır ve network teknolojilerinin sınırlılıklarını ve hatalarını keşfe çıkar. Bazı önemli örnekleri, İnternet tarayıcılarının gizil yapısını görünür kılarak baş aşağı çeviren The Web Stalker ${ }^{53}$; harfleri görsel imajlar olarak kullanarak, metinle görsel imajların bilgisayara yüklenme süreleri arasındaki farkı ve böylelikle protokolün kendisini bir sanat projesine dönüştüren Will-n-Testament; ${ }^{54}$ ve TEXT RAIN'dir. ${ }^{55}$ Galloway'in ikinci aşama olarak konumlandırdığı Yazılım (Software) sanatı ise, şirketlerin para kazanma pratiklerini kültür alanında estetize etme pratiklerine karşı, bu para kazanma pratiklerinin şirketlerin kendi alanında estetize edilmesine dayalı bir tür protesto olarak ortaya çıkar. Sembolik doğuşu, İsviçreli sanatçı Etoy'un, çoklu kullanıcılı bir oyun platformu olan Toywar ${ }^{56}$ adında bir yazılım yaratarak, eToys Inc'in NASDAQ hisselerinde \%50'nin üzerinde bir düşüş yaratması sonucunda kendisine açılan davayı kazandığı 25 Ocak 2000 tarihidir. Bu eylem, 4.5 milyar dolar değerinde tarihin en pahalı sanat performansı olarak anılır. Bu pratiğin sonraki örnekleri ise eBay sanatı ve auctionizmdir.

Yeni mecra sanatı alanındaki denemeler ve dijital estetik alanındaki tartışmalar, teknoloji ve sanat/kültür arasındaki kadim bağı ki bu bağ yücenin estetiğine olan inanca ve "yaratılmamış yaratıcı olarak sanatçı" imgesine dayalı modern dönemin pratiklerinde silinmeye ve görünmezleştirilmeye çalışılmıştır, tekrar görünür kılmıştır. Teknoloji, öncelikle üretim ve rasyonelleşmeyle beraber, minimum girdi/maksimum çıktı rasyonalitesine eklemlenmiştir. Fakat deneysel sanatsal ve estetik alan, teknolojiyle sistemin normundan sapmak amacıyla angaje olmuştur. Sanat ve mecrası arasındaki ilişkiyi tekrar görünür kılan ve politik yeni imkânlar yaratan bu uğraşı, popüler ethos'un pragmatizmden ve faydacılığından da mesafelenerek, kapitalizmin çevrimine ve bilimin temsilci epistemolojisine bir meydan okumayı içermektedir.

\section{Deneysel Șiir, Elektronik Edebiyat ve "Dijital'in Po(e)litikası"}

Stéphane Mallarmé'nin şiirlerinin başlangıç noktası olarak kabul edildiği modern deneysel şiir, başta Fransa'daki Lettrist ve Almanya ve Brezilya'daki Somut şiir hareketleri gelmek üzere, Dada deneyleri, İtalya' daki ve Rusya' daki fütürizm hareketi, Britanya'daki Vorticist grup ve e. e. cummings ve Bob Brown gibi Anglo-Amerikan sanatçılarının pratiklerinden oluşur. ${ }^{57}$ Politik ve 
estetik kaygılarla mobilize olan bu hareketlerin bazıları, 1920 ve 1930'lardaki milliyetçilik hareketlerine bağlandılarsa da birçoğu, ütopyan dönüşümler ve muhalif yıkıcılık peşine düştüler. Bu deneyleri birleştiren temel kaygı, dilin fizikselliğini öne çıarmak, dilin görsel niteliklerinin manipülasyonu ve teknolojik ortamlarla deneylerdi. Kenneth Goldsmith, görsel ve dijital şiirin temel kaynaklarından olan Somut şiir hareketinin ${ }^{58}$ tarihini, 1960'lardaki Helvetica yazı karakteri üzerinde dönen ideoloji savaşları bağlamında okur. ${ }^{59}$ 1970'lerde, toplumsal, politik ve teknolojik nedenlerle Helvetica'dan kopan ve 20. yüzyılın ikinci yarısının gizli tarihine gömülü olan Somut şiir hareketinin ütopyadan distopyaya uzanan tarihi, kültürel üretim süreçlerinde meydana gelen daha geniş dönüşümlere paralel olarak ilerler. Bu yazı karakterinin hem estetik hem politik olarak reddedilmesi, Helvetica'nın, Soğuk Savaş'tan miras ikiliklerin, endüstriyel-militer kötülüklerin bir cisimleşmesi ve muhafazakâr (erkek) insanın temsili olarak görülmesinden ve tek boyutlu hatlarının, günün darmadağınık dünyasına uygun olmadığı düşüncesinden kaynaklaniyordu. Noigandres grubu ve Agusto de Campos gibi öncülerin etrafında şekillenen Brezilya'daki hareket, Somut şiir deneylerinin en etkili akımı olarak görülür. Bu hareket, örneğini, 20. yüzyılın reklam sloganlarında, logo ile işaretlerinde bulduğu evrensel bir resim dili ve toplumun kentselendüstriyel çevresine müdahale edebilecek yeni hissiyat biçimleri yaratma ütopyasının peşine düşmüştü. ${ }^{60} \mathrm{Bu}$ hareket, İngiltere, Fransa, Almanya, Portekiz, İspanya, Macaristan, Kanada, ABD ve Japonya'dan benzer dertlerle yola çıkan şairlerle de birleşerek uluslararası bir harekete dönüştü. Brezilya'daki 1964 askeri darbesi ve sonrasında uzun yıllar sürecek olan totalitaryanizm dönemi, bu politik ve ütopyan deneyleri sekteye uğrattıysa da, modernizmden kopan, de Campos'un "post-ütopyan" olarak nitelediği, yeni deneyler ortaya çıktı. ${ }^{61}$ Kanada ve İngiltere'de ortaya çıkan 2. somut şiir dalgası, 1950 ve 1960'ların modernizmden ilham alan ilk evresinden koparak, "daktilonun gürültüsünü"nün peşine düştü ve şiir yazımında makinanın varlığını görünür kılmaya çalışan "kirli somut" hareketine evrildi. ${ }^{62}$ Burjuva şiiri olmayan bir şiirin peşine düşen bu şairler, teksir ve fotokopi makinalarının, daktilonun isli kirinin peşine düştüler ve doğrusal olmayan, okunaksız şiirler aradılar. 1968 hareketiyle, somut şiir, kâğıt yüzeyini terk edip sokağa çıktı ve sitüasyonizmden ilham alan grafittiler olarak kent duvarlarını işgal etti.

Derek Beaulieu, evrensel bir dil peşinde reklam dilinden etkilenen modern somut şiirin aksine, çağdaş somut şiirin, sloganlaştırma ve reklamcılığın evrensel dilinden uzak durduğunu belirterek, "yazı biriminin demontaj ve yeniden montajıyla dilin kapitalist değer üretimini kırmaya çalıştığını" söy- 
ler. ${ }^{63}$ Böylece, çağdaş somut şiirin politikliğinin birinci ekseni, okurun anlam arayışını kesintiye uğratarak, anlamlandırmaya müdahale etmesinde ve "bir an için dilin kapitalist yapısını kesintiye uğratması" çerçevesinde eklemleniyor. Buna göre, alfabe, kapitalist hegemonyanın boyunduruğu altındadır ve "kapitalizm sözlüğü açttğınızda başlar." Dille kopuş, bu anlamda, politik ve ekonomik olana karşı çalışır. Makinanın, niyet edilmemiş, sistem tarafından belirlenmemiş ve ekonomik kullanımına karşı konumlanan amaçlarla şiire eklemlenmesi ${ }^{64}$ dijitalin politikasının ikinci ekseni olarak ortaya çıkıyor.

Böylelikle, politika, teknoloji ve estetiğin kesişimselliğinde Somut şiir, Goldsmith'in deyimiyle, "dijital bir zümrüd-ü anka kuşu" olarak 21. yüzyılda post-dijital somut şiir olarak yeniden yükselişe geçti. ${ }^{65} \mathrm{Web}^{\prime}$ in yardımıyla, bu arayışlar uluslararası hareketler olarak ortaya çıktılar. Dijital teknolojilerin ve İnternet'in kodlanmış dile dayalı doğası, Web'in dili ile ağ, dilin çokboyutluluğunun ve mecrasını merkeze alarak şiirin ne'liğinin peşine düşen ve kendilerini ütopyan ideolojik bir savaşın içinde mevzileyen Somut şiir için, hayal edilemez yeni imkânlar sunuyor. Philadelpho Menezes, 20. yüzyılda ortaya çıkan deneysel şiiri, yazının krizi ve göstergelerarasılığın meydan okuması bağlamına yerleştirerek, ihlal ve yabancılaşma arayışında olan ilk dönem teknolojik evrenin ve avangart hareketin devrimci ütopyasının yerini, ikinci dijital teknolojik evrenin aldığını ve çoklu göstergelerle yeni bir tür ilişkiye girme süreci anlamına gelen bu evrenin, dünyanın yeniden bulunuşu ve dönüşümünü ifade eden çoğulütopya (pluritopia) tarafından destekleneceğini öne sürüyor. ${ }^{66}$

Frank Cormerias, "dilbilimsel dönemeç"ten sonra, mekanize yeniden üretim teknolojilerinden farklılaşarak kitle iletişim çağını dönüştüren dijital yaratım teknolojileriyle yeni bir "teknolojik dönemeç" e girdiğimizi söylüyor. ${ }^{67}$ Cormerias'a göre, bu durum, "denetime ve estetik koşullanmaya adanmış aygitların" çağında, "yapılış ve davranış bilgisinin yeni biçimlerinin" ve "makinasal dişsallaştırmanın dijital evresinde gizil olarak içerilen yeni varoluş kipliklerinin" ortaya çıkışı uğruna verilecek bir savaşı zorunlu kılıyor. Sanatın, teknik dolayımıyla bir nesne üretim pratiği olduğunu unutturan, sanat ve tekniği birbirinden ayrıştıran Batı geleneğine gömülü ikili karşıtlıkları sorgulama imkanı veren techne'nin bu geri dönüşü, yapma ve söyleme arasında kurulan geleneksel ilişkiyi tersyüz eden ve önceki avangart hareketlerin sorunsallarını yerinden eden bir dijital po(e)litika ortaya çıarıyor. Aynı zamanda, bu po(e)litika, Batı'da teknobilimsel rasyonalitenin içinde inşa edilegelen teknolojiyi, yeniden sorgulama imkânı veriyor. Bu imkân, dile ve bilime indir- 
genen üretimi, bu dayatmalardan kurtarma ve yapmanın statüsünü, poetika/ teknik, metin/sayı, sanat/bilim, özne/nesne, yapı/ilişki arasında kurulan eski ikiliklerde gedik açan "dijital nesnenin nesnelliği" bağlamında düşünme imkânıdır. Unutulmuş bir tarih olarak "Poitein" (yani, yapmak, üretmek, iş dolayımıyla gerçekleştirmek) kökünden gelen şiir ("poiema") ve şair ("poietes"), dijitalin poetikası (yani dijitalin yapımı) ile "kendini ifade edebilen bir yapma” eyleminin mecrası olur; "imal etmenin, algının, alımlamanın ve bilişin, ifade malzemesinin (gösterge, ses, metin) dijital kodlanışıyla ilintili yeni düzenleri" üzerine düşünmeyi mümkün kılar. Yazılımları ve teknik formatları harekete geçiren bu yapım, sanatı toplumsal pratiklere yaklaştıran açık, katılımlı bir yapımdır. Cormerias'a göre, "şiirin kendisi kültür endüstrisinden silinirken", bu yeni dönemeç, "poetikayı" öne çıkarır. Dijitalin bu poetikası, politiktir çünkü “duyarlığı biçimlendirmeyi ve imgeleme yön verici şemalar önermeyi amaçlayan estetik savaşın bağlamında konuşlanır ve harekete geçer. Bu estetik savaşa, duyarlığın savaş bilimi [polemoloji] (tinlerin savaşının psikolojik ve toplumsal olarak incelenmesi) eşlik eder. Po(e)litika, politik olanın ve sanatın alanının genişlemesi" bağlamında konumlanır.

Foucault, 18. yüzyıla kadar "bir toplumsal grubun içinde dolaşmayı hedeflemiş olan sözün destekçisinden başka bir şey" olmayan yazının, 19. yüzyıldan itibaren "salt kendisi için", "her tüketimden, her okurdan, her zevk ve yarardan bağımsız olarak" var olmaya başladığını ve "yazının bu dikey ve neredeyse aktarılamaz faaliyeti" nin, "bir anlamda dikey duran bir dil ve her türlü değişim değerini yitirdiği için artık aktarılabilir olmayan söz" olan deliliğin dengi olduğunu yazar. ${ }^{68}$ Bu "dolaşımcı olmayan edebiyatın”, "başka yerde imkânsız olan ihlalin mümkün olduğu bir kurum halini" aldığını söyler. ${ }^{69}$ Foucault'un bahsettiği edebiyat, yine de, "duyularla ve geçicinin, sıradışının, trajiğin, acının, korkunun, dokunmanın, melankolikliğin atmosferiyle" 70 bağlantılı bir öznelliğe dayanıyordu. Bu öznelliğin yerini, yeni medyanın, dijital teknolojilerin, sibernetik ve enformasyon dünyasının "fraktal öznesi" almaktadır. ${ }^{71}$ Elektronik edebiyat, doğal dillerin, İnternet dilinin, senaryo yazımının ve programlama dillerinin birleştiği, görsel, hareketli ve dokunsal yapıları ve navigasyon deneyimlerini içeren genişletilmiş bir metinselliğe dayanan, melez bir metindir. Kinetik e-şiir versiyonunda ise metin, "döngü moduna giren zaman-serisi temelli kelimefilm, bitişiklikler ve ayrılmalar, benzerlikler ve benzeşmezlikler, gerilimler ve boşalmalar gerektiren çeşitli poetik dizimler"den ve yatay ile dikey hareketlerin zamansal düzenlenmesinden oluşur. ${ }^{72}$ Okuyucu, "mouse okuma" ile kelimeler üstüne tıklayan, bağlantı açan ve bilgisayar programını aktif hale getiren bir metin kullanıcısıdır. Bu öznel- 
lik, doğrusal değil, zıplamalı bir okumayla, kelimeleri 3-boyutlu nesneler biçiminde görerek, dokunarak ve yakınlaştırarak, multimedya tasarısı nesneleri dinleyerek, metnin olumsallığına katılır.

Katherine Hayles, çeşitli yazılımların ve navigasyon sistemlerinin, edebi ve sanatsal pratiklere içerildiği, dijitalin dilini konuşan ve "makinanın derinlikleri" ne inmeyi amaçlayan ikinci jenerasyon hiper metinlerin, teknolojinin biçim ve işleve gömülü varsayımlarını tersyüz ederek ifşa ettiğini söyler. Hayles'e göre nasıl ki her toplumsal dönem, olmakta olanı anlamaya çalışan bir edebiyata yol verdiyse, elektronik edebiyat da, postinsanlık durumumuzu kavrama çabalarının edebi bir ifadesidir. ${ }^{73}$ Öte yandan, Goef Huth, insanın kendi ürettiği teknolojinin ve özellikle de onu kullanarak yaratma imkânı veren dijital teknolojilerin, insana sadece bir parçası olduğu doğadan daha yakın olduğunu söyleyerek, okuyucudan gelen tepkilere izin veren dijital teknolojileri, "hem insan, hem de teknolojik olandan yaratılmış organizmalar olan (cyborg)" insanın daha insani olmasına, daha kendi olmasına yardım edebilecek bir imkân olarak görüyor. ${ }^{74}$

Özet olarak, hemen hepsi deneysel edebiyat ve dijital üretimle iştigal olan sanatçıların içeriden eleştirileri bağlamında ilerletilen bu tartısma, sanat ve dijital teknolojilerin karşılaşmasında politikanın dört temel eksen çerçevesinde eklemlendiğini gösteriyor: Teknolojinin niyet edilmeyen, kontrole ve artı-değer üretimine dayalı araçsal rasyonel kullanımından saparak teknolojiye dair sorgulamalara girişmek; kod olarak ortaya çıan dil içerisinden yeni imkânlar yaratmak ve dolayısıyla belgeyle değil programla uğraşmak; techne ve sanatı ayıran, söylem ve bakma rejimlerini belirlemiş olan modern Batı geleneğinden koparak, tekniğin dönüşünün mümkün kıldığı sanat ve yapım arasındaki ilişkiyi yeniden keşfetme imkânını gidebildiği yere kadar ittirmek ve son olarak analog hayattan dijital hayata geçişte postinsan durumunu ya da bizatihi insani olarak nitelene gelen şeyi yeniden keşfetmek ve ortaya çıkan yeni öznellikleri kavrama çabasına girişmek. Bu dört ekseni kesen temel müdahale hattı ise, Cormerias'ın ifade ettiği gibi, bütün duyuları işe katma imkânı veren yeni mecra içerisinden duyarlığı biçimlendirmek, imgeleme yön vermek ve Jackson'ın da ifade ettiği gibi hala akışkan halde olan yeni teknolojilerin anlamını müzakere etmektir.

Türkiye'de de, dijitale yönelik soruş̧turmaların ve bu soruşturma içerisinden toplumsala müdahaleye dair yeni mevzilerin belirdiği temel mecralardan birinin yine şiir alanı olduğu söylenebilir. Türkiye edebiyatında, Nazım Hikmet, Ercümend Behzad Lav ve İlhan Berk gibi deneysel unsurlara şiirlerinde 
yer veren şairlerin yanı sıra, Akgün Akova, Yüksel Pazarkaya ve Tarık Günersel gibi tekil somut şiir denemeleri yapan şairler ortaya çıksalar da ${ }^{75}$ şiir ve mecra arasındaki ilişkiyi sorunsallaştırarak bir poetika ortaya koymaya çalışan ilk kişi Hüseyin Cöntürk'tür. ${ }^{76} 2000$ sonrasında, Türkiye'de, Cöntürk'ü yerel öncüleri kabul eden, İnternet'i temel mecra olarak alarak, teknolojiye dair soruşturmalara girişen hareketin Zinhar / Poetikhars çevresi ${ }^{77}$ olduğu söylenebilir.

Hareketin kurucu ismi Serkan Işın, yazının cismaniliğinin kanıtı olarak gördüğü İnternet'i, “dilin bir teknoloji olarak geldiği nokta"yı gösteren ve "dilin kendisinin kendi kendisi için var olabildiği ve bu yüzden şiir ile benzerlikler" taşıyan tek mecra olarak işaretler. ${ }^{78}$ Internet, "yazı teknolojisinin en yüksek yeridir, henüz yıkılmamış bir babil: e-babildir." Bir parça kod ile ağa geçici hasar verebileceğiniz kadar "cismani, gerçek ve somuttur." Sözlüğe takılıp kalmaktansa, "göstergenin kendi boyutlarını katladı̆̆ı yeni bir mecra olarak İnternet’i şiir için sınamak" gereklidir. ${ }^{79}$

Bu hareket, bilgisayarın, hayatın her alanına girdiği toplumsal koşullarda, herhangi bir işletim sisteminin, Türkçe ile çalışılabilecek herhangi bir bilgisayarın, yazılım sistemlerinin, tarayıcı ya da fotokopi makinalarının, bilgisayar hata mesajlarının ve kazalarının, edebiyatta yerini alması gerektiği iddiasıyla yola çıkmıştır. ${ }^{80}$ Alfabeyle, tarayıcılarla, yazılımlarla ve İnternet'le şiir yapımı öne çıkar. Modern edebiyat ve sanatların teknolojiyle kurdukları ilişkiden kopuşun bir göstergesi olarak "eser" terimini ret ederek, "iş" olarak adlandırmayı tercih ettikleri şiirler ${ }^{81}$ ile görsel ve dijital şiirle ilgili çeviriler yayınlar. Bu hareket, sözel/edebi şiirin, "bizi habire inşa edip sonrasında da yapı-bozumuna tabi tutan" yeni toplumsal koşulların görsel/metinsel kültürel araçlarına tepki vermeye artık muktedir olmadığını ileri sürerek, 21. yüzyılın kodlanmış yaşamlarına karşı, bu kodları yapı-bozumuna uğratacak görselleştirme ve metinselleştirme denemelerine girişir. Şiiri, şehir yaşamınca empoze edilen kodlara müdahaleler yoluyla anti-kod üretmesi gereken bir mekanizma olarak anlar. ${ }^{82}$ Işın, sitüasyonist bir başlıkla yazdığı bir yazısında, görsel şiiri, "endüstriyel yazma tekniklerinin etkilerinden kurtulmaya çalışmak"; tüketim kültürüne karşı "reklamı, cıngılı yapılamayacak hallerimizin şiiri”ni yazmak; "okurun, bakanın, gösterge ile metnin derinliklerindeki bir zaman içinde ödüllendirilmesine karşı çıkılması"; ve "harfleri, daktiloyu, mürekkebi, bilgisayarı, dizeleri, bu kelimeleri başka indirgenecek şeyleri kalmayana kadar elemek, elemek ve unufak etmek" olarak açıklar. ${ }^{83}$

Daha önce herhangi bir teknolojik aygıtla deneye girişmediğini iddia ettikleri Türkiye'deki şiire karşı bir meydan okuma olarak da ortaya 
çıkan bu hareket, "deney yaptıkları bağlamı kurmayan”, "bir zamanlar denenmiş çalışmaları Türkçeye tercüme etmekten başka bir şey yapmayan", "Türkiye'deki gelenekle şiir-içi hesaplaşmaya girişmeyen" ve "sahicilik inşa etmesi gereken" 84 bir hareket olarak görülmüştür. Ana mecra olarak İnternet'i seçmiş olması da ayrı bir eleştiri hattıdır. ${ }^{85}$ Şiir alanındaki ana akım polemiklerde, "teknoloji sevicilik" ve görsellikle şiirin yozlaştırılması iddiası üzerinden reaksiyoner tepkiler alsalar da, değişen koşulların ve teknolojik dönüşümlerin şiiri dönüştürdügünün bir işareti ve "medyanın ve iletişim aygıtlarının dayatmasına karşı bir şair saldırısı" olarak da olumlanmıştır. ${ }^{86} \mathrm{Bu}$ hareket, başat kozun sembolik sermaye olduğu alan mücadelelerinden nasibini almıştır. ${ }^{87} \mathrm{Bu}$ harekete verilen tepkinin temelinde yatan teknofobi, ironik bir şekilde hem muhafazakâr sağda hem de sol cenahta, Batı kapitalizmine ve emperyalizmine bir direniş olarak tezahür etmektedir. Ama direniş, teknolojinin yekten reddi midir yoksa ona müdahale yollarını aramak ve anlamını müzakere etme çabasına girişmek midir?

\section{Sonuç}

Bu makale, belirmekte olan dijital sanat pratikleri bağlamında, yeni muhalefet ve müdahale biçimlerini tartışmaya açmayı amaçlamıştır. Bu yeni direniş biçimleri, sisteme karşı örgütlü bir hareket olarak değil ama postfordist kontrol toplumu koşullarında, kod etrafında yapılanan iktidar pratik ve süreçlerine, dijital kapitalizmin mecrası olan yeni teknolojik biçimlere, sistemin ilişkilenme biçimlerinin dışına çıkarak müdahil olmaya çalışan hareketler olarak ortaya çıkmaktadır. Üretim tarzlarıyla görece özerk kültürel üretim alanı arasındaki karşılıklı ilişkiler, ağ toplumu olarak örgütlenmiş geç kapitalist koşullarda yeni biçimler almıştır. Bu biçimler, yeni toplumsal koşulların kültürel alanda kendini nasıl meşrulaştırdığı ve yeniden ürettiği sorunsalının ötesine geçerek, şimdiye ve geleceğe nasıl müdahil olunabileceğine dair olumsal bir pratik olarak kendini konumlandıran yeni mevzilerin nasıl üretilmekte olduğunu da ortaya koymaktadır. Son olarak, Dijital kapitalizmin metropollerinde ortaya çıkan bu yeni konumlanmalara paralel bir şekilde, Türkiye'deki kültürel üretim alanında belirmekte olan ve alan içindeki eski konumlarla mücadele halinde olan yeni hareketlerin nüvelerini görmek de mümkün hale gelmiştir. 


\section{Notlar}

1 1970'ler, farklı kavramsallaştırmalardan ve yaklaşımlardan hareket etseler de pek çok farklı analizde postmodernitenin miladı olarak kabul edilir. Örneğin, Charles Jencks postmoderniteye geçişin sembolik tarihini St. Louis'deki Pruitt-Igoe toplu konut bloklarının dinamitle havaya uçurulma tarihi olan 1972, saat 15.32 olarak vermiştir. 1970'ler, aynı zamanda İtalya'daki İşçicilik Hareketi'nin (Operaismo) mücadelesinin ve "emek-zamanının azalması ile teknik bilgi ve toplumsallaşmış zekânın uygulanması yoluyla üretimin dönüşümü" arzusunun postfordizmin ortaya çıkışına götüren dinamikler yaratmasının tarihidir (Sylvère Lotringer, “Önsöz: Biz Çokluğuz," Çokluğun Grameri içinde (İstanbul: Otonom, 2005), 8). ABD’nin 1971'de Bretton Woods Anlaşması'ndan çekilişi ve 1970’lerdeki aşırı birikim krizi de David Harvey açısından postmodern durumu ortaya çıkaran ekonomi-politik dönem noktalarıdır (David Harvey, Postmodernliğin Durumu, çev. Sungur Savran (İstanbul: Metis, 1997). JeanFrançois Lyotard ise 1979' da postmodern durumu ilan etmiştir (Jean-François Lyotard, Postmodern Durum, çev. Ahmet Çiğdem (İstanbul: Ara, 1990).

2 Alexander R. Galloway, Protocol: How Control Exists After Decentralization (Cambridge: MIT Press, 2004), 29, 200; Pramod K. Nayar, An Introduction to New Media and Cybercultures (Malden, MA: Wiley-Blackwell, 2010), 26.

3 Manuel Castells, Enformasyon Çă̆ı: Ekonomi Toplum ve Kültür, 1. Cilt, A Ă Toplumunun Yükselişi, çev. Ebru Kılıç (İstanbul: İstanbul Bilgi Üniversitesi Yayınları, 2005).

4 Daniel Schiller, Digital Capitalism: Networking the Global Market System (Cambridge, MA: MIT press, 1999).

5 Allison Cavanagh, Sociology in the Age of the Internet (Maidenhead: McGraw Hill/Open University Press, 2007), 38, 40, 161.

6 Michael Hardt ve Antonio Negri, Imparatorluk, çev. Abdullah Yılmaz (İstanbul: Ayrıntı Yayınları, 2001); Paolo Virno, Çokluğun Grameri, çev. Volkan Kocagül ve Münevver Çelik (İstanbul: Otonom Yayıncilık, 2013).

7 Eugene Thacker, "Foreword: Protocol is as Protocol Does," Protocol: How Control Exists After Decentralization içinde, Allison Cavanagh (Cambridge: MIT Press, 2004), xviii.

8 Gilles Deleuze, Foucault, çev. Sean Hand (Minneapolis: University of Minnesota Press, 1986), 35; aktaran Galloway, Protokol, 3, 22.

9 Thacker, "Foreword," xvi.

10 Gilles Deleuze, "Postscript on the Societies of Control," October 59 (1992): 5.

11 Deleuze, "Postscript," 6.

12 Ergin Bulut ve Ayhan Ayteş, "Giriş: Dijital Emek, Dijital Kültür," Toplum ve Bilim 135 (2015): 4-5; Utku Özmakas, “İnsan Sermayesinin Kaynağ1: Maddi Olmayan Emek,” Toplum ve Bilim 135 (2015): 15; Ergin Bulut, “Cyber-Proletariat Üzerine Nick Dyer-Witheford ile Söyleşi," Toplum ve Bilim 135 (2015): 161.

13 Özmakas, “İnsan,” 25. 
14 Andrea Langlois ve Frédéric Dubois, der., Otonom Medya: Direnişi ve Muhalefeti Canlandırmak, çev. Gülüm Şener (İstanbul: Kafka Yayınevi, 2015).

15 Deleuze, "Postscript," 6.

16 Jean-François Lyotard, Postmodern, 43.

17 Galloway, Protokol, 16-17.

18 Galloway, Protocol, 13, 16.

19 Friedrich A. Kittler, Discourse Networks, 1800/1900, (Stanford: Stanford University Press, 1990), 369.; aktaran Galloway, Protocol, 18, 22-23.

20 Thacker, "Foreword," xvi.

21 Larry Shiner, Sanatın İcadı: Bir Kültür Tarihi, çev. İsmail Türkmen (İstanbul: Ayrıntı Yayınları, 2004), 23. Her ne kadar günümüzde, üretimle ve toplumsal bağlamıyla sürekliliği koparılmış ve "tinsel" alana daraltılmış olsa da sanata dair kelimelerin kökleri, bu hafızayı saklı tutmaktadır. Text kelimesinin kökü "dokumak" fiilinden gelir (Walter J. Ong, Sözlü ve Yazılı Kültür, çev. Sema Postacıoğlu Banon (İstanbul: Metis, 1991), 26). Kabyle dilinde şiirin isimlerinden biri asefru (çoğulu: isefra) tahılı ayrıştırmak anlamına gelen fru fiil kökünden gelir ve ozan, "karıştırılan şeyleri ayıran, müphem şeylere ışık tutan" ve "oyunun kuralı ile oynayarak oyunun hakikatini açığa çıkarma" ayrıcalığına sahip olarak görülür (Mouloud Mammeri ve Pierre Bourdieu, "Dialogue on Oral Poetry," çev. Richard Nice ve Loïc Wacquant, Ethnography 5, (4) (2004): 511-512.

22 Theodore W. Adorno, Minima Moralia, çev. Ahmet Doğukan ve Orhan Koçak (İstanbul: Metis, 2005), 234.

23 Ong, Sözlü, 20, 97.

24 Ong, Sözlü, 21, 44.

25 Ong, Sözlü, 140.

26 Ong, Sözlü, 33-35.

27 Ong, Sözlü, 153.

28 Vilém Flusser, "On Memory: Electronic or Otherwise," Leonardo 23, (4) (1990): 397-399.

29 Friedrich Kittler, "There Is No Software," Electronic Culture içinde, der. Timothy Druckrey (New York: Aperture, 1996), 332; aktaran Galloway, Protocol, 166.

30 Galloway, Protocol, 165-169.

31 Cavanagh, Sociology, 143.

32 Dijital kültürle birlikte cinselliğin dönüşümü ve kadın temsillerine dair feminist eleştiriler için bkz., Claudia Springer, Elektronik Eros, çev. Hakan Güneş (İstanbul: Sarmal Yayınevi, 1998).

33 Cavanagh, Sociology, 144. 
34 Jonathan Crary, Gözlemcinin Teknikleri: On Dokuzuncu Yüzyllda Görme ve Modernite, çev. Elif Daldeniz (İstanbul: Metis, 2004).

35 Crary, Gözlemcinin, 31.

36 Pierre Bourdieu, vd., Photography: A Middle-Brow Art, çev. Shaun Whiteside (California: Stanford University Press, 1990), 8.

37 Bourdieu, Photography, 77.

38 Bourdieu, Photography, 104-105.

39 Nayar, An Introduction, 50.

$40 \mathrm{Bu}$ tartışmada, insanın neliğini sorgulayan, bedenin sınırlarını ve kategorilerini yeniden tanımlayan genomic sanatları, biomedya ve post-insan sanatını dışarda bırakıyorum.

41 Glen Creeber, "Digital Theory: Theorizing New Media," Digital Cultures: Understanding New Media içinde, der. Glen Creeber ve Martin Royston (Maidenhead: Open University Press, 2009).

42 Thacker, "Foreword," xiv. Ayrıca bkz., Nayar, An Introduction, 57.

43 “Virtual," erişim tarihi 23 Mart 2016, http:/ / www.etymonline.com/index.php?allowed_in_ frame $=0 \&$ search $=$ virtual.

44 Timothy Allen Jackson, "Towards a New Media Aesthetic," Reading Digital Culture içinde, der. David Trend (Malden, MA: Wiley-Blackwell, 2001), 352.

45 Jackson, "Towards," 348-349.

46 Galloway, Protocol, 245.

47 Galloway, Protocol, 209.

48 Taktiksel medyaya bir örnek olarak, reklam göstergelerinin, şirketlerin kar elde etme stratejilerini veya iktidar baskısını afişe etmek amacıyla parodi yoluyla politik olarak yeniden işlenmesi, "kültür sinyali boğma" (culture jamming) anlamına gelen subvertisement olarak adlandırılan (Nayar, An Introduction, 34) işler için bkz., "Adbusters," erişim tarihi 26 Mart 2016, http://adbusters.org/.

49 Galloway, Protocol, 176.

50 Galloway, Protocol, 190.

51 Galloway, Protocol, 213.

52 Galloway, Protocol, 219.

53 Galloway, Protocol, 218; “The Web Stalker," V2, erişim tarihi 26 Mart 2016, http: / v2.nl/archive/ works/the-web-stalker.

54 Galloway, Protocol, 224; “Will-n-Testament,” Teleportacia, erişim tarihi 26 Mart 2016, http:/ / will.teleportacia.org/.

55 Nayar, An Introduction, 53; Camille Utterback ve Romy Achituv, “Text Rain," Camilleutter- 
back, 1999, erişim tarihi 26.03.2016, http:/ / camilleutterback.com/projects/ text-rain/.

“Toywar," Etoy, erişim tarihi 26 Mart 2016, http:/ / toywar.etoy.com/.

57 Johanna Drucker, “Visual Poetics: An International View," boundary 2 26, (1), 1999: 100.

58 Klaus Peter Dencker, Somut şiir kavramının ortaya çıkışını şöyle anlatıyor: "Somut şiir kavramı, İsveçli sanatçı Öyvind Fahlström'ün 1953'te yazdığı bir manifestoda ortaya çıktı. Eugen Gomringer, 1954'te yazdığ 1 "Dizeden Düzenlemeye" isimli manifestoda kavramı kullanmaksızın somut şiiri tanımlamış ve tasvir etmiştir. Kavramı ilk kullanışı ise $1956^{\prime}$ da Brezilyalı Noigandres grubu temsilcileriyle Ulm Üniversitesi'nde görüştükten sonradır (Klaus Peter Dencker, “Elektronik Geleceğe Bir Bakışla Somut Şiirden Görsel Şiire,” çev. Gözde Karabalık, Karagöz 5, (2008): 28).

59 Helvetica belgeseli hakkında, erişim tarihi 18 Nisan 2016, http://www.imdb.com/title/ $\mathrm{tt} 0847817 /$.

60 Kenneth Goldsmith, "Make It New: Post Digital Concrete Poetry in the 21st Century," The New Concrete: Visual Poetry in the 21st Century içinde, der. Victoria Bean ve Chris McCabe (Londra: Hayward Publishing, 2015), 11.

61 Goldsmith, "Make," 12.

62 Goldsmith, "Make," 12.

63 Derek Beaulieu, "Sözcüklerden Sonra Sonsöz: Somut Şiire Doğru Notlar," çev. Suzan Sarı, Poetikhars (blog), 18 Mart 2007, erişim tarihi 19 Nisan 2016, http: / / poetikhars.com/webblog/ bibliobot/sozcuklerden-sonra-sonsoz-somut-siire-dogru-notlar.

64 Örneğin, daha erken dönemde Darren Wershler, "photoyıkım" ("photodestroy") olarak adlandırdığı bir teknikle, dijital medya ortamında, bir yaranın kapanması sürecinde oluşan izlerin peşine düştü (Drucker, "Visual," 102). Diğer daha erken dönem deneylerin bir envateri için bkz., Drucker, "Visual."

65 Goldsmith, “Make," 10

66 Philadelpho Menezes, "Göstergelerarası Şiir: Kültürün Teknolojikleşmesinde Görsel ve Sessel Şiir," çev. Suzan Sarı, Poetikhars (blog), 16 Mart 2007, erişim tarihi 18 Nisan 2016, http:/ / www.poetikhars.com/webblog/bibliobot/gostergelerarasi-siir.

67 Franck Cormerais, "Dijitalin Poetikası," çev. Zeynep Cansu Başeren, Poetikhars (blog), 26 Temmuz 2010, erişim tarihi 18 Nisan 2016, http:/ / www.poetikhars.com/dijitalin-poetikasi.

68 Michel Foucault, "Delilik, Edebiyat, Toplum," Sonsuza Giden Dil (Seçme Yazılar 6) içinde, çev. Işık Ergüden (İstanbul: Ayrıntı Yayınları, 1994), 271.

69 Foucault, “Delilik,” 275.

70 Janez Strehovec, “Döngü Olarak Metin/ Dijital Şiir Üzerine,” çev. Gökçen Ertuğrul, Zaman Çuvalı (blog), 22 Mart 2014, erişim tarihi 28 Mart 2016, https://zamancuvali.wordpress. com/2014/03/22/dongu-olarak-metin-dijital-siir-uzerine-2/.

71 Strehovec, “Döngü,". 
72 Strehovec, "Döngü,".

73 Katherine Hayles, "Deeper into the Machine: The Future of Electronic Literature," Culture Machine 5 (2003), erişim tarihi 28 Mart 2016, http:/ / culturemachine.net/index.php/cm/article/view/245/241.

74 Geof Huth, “Şiir, Teknoloji, İnsanlık,” çev. Deniz Tuncel, Karagöz 5 (2008): 16-17.

75 Bir değerlendirme için bkz., G. Gonca Gökalp-Alpaslan, “Türk Edebiyatında Somut (Görsel) Şiir," Türkbilig 10 (2005): 6-9; Gökhan Tunç, "Çağdaş Türk Edebiyatında Görsel Şiir," bilig 73 (2015): 249-270.

76 Serkan Işın, Tü̈̆üun, (Ankara: Ebabil, 2007), 185.

77 Zinhar.com, Deniz Tuncel, Derya Vural, Barış Özgür, Özcan Türkmen, Tarık Günersel, Ali Ömer Akbulut, Evrim Önk, Şakir Özüdoğru, Aslı Serin'den oluşan kurucu kadrosuyla, 2003'te bir wesitesi ve elektronik olarak yayınlanan bir dergi olarak ortaya çıtı. Suzan Sarı, Ayşegül Tözeren ve Zeynep Cansu Beşeren gibi isimler de bu oluşuma sonradan katılmıştır. İlk sayısı "MerkezKaç" başlığıyla yayınlanmıştır.

78 Işın, Tü̈̆̈̈̈n, 186.

79 Işın, Tüğün, 185.

80 Işın, Tüğün, 5-6.

81 İşler için bkz., "zinharpost: görsel şiir türkiye'de görsel şiir (visual poetry in turkey)," Zinharpost (blog), erişim tarihi 28 Mart 2016, http:/ / www.zinharpost.blogspot.com/.

82 “Guidebook for Visual Poetry," Poetikhars (blog), 17 Mart 2007, erişim tarihi 28 Mart 2016, http:/ / www.poetikhars.com/webblog/telebeing/guidebook-visual-poetry.

83 Serkan Işın, “Semiyotik Gerilla Savaşı: Görsel Şiir,” Yasakmeyve 28 (2007): $42-43$.

84 Bu eleştiriler için bkz., Enis Akın, “Şiirimizin Serüveninde Son 30 Yıl," Karagöz 5 (2008): 45.

85 Bu tür eleştiriler için bkz., Ali Görkem Userin, “Sözden Göze Evrilen Şiir,” Karagöz 3 (2008): 51-52.

86 Evren Kuçlu, "Şiirin Tüğünü," Karagöz 3 (2008): 54-55.

87 Bu dönemin edebi mücadeleleri bağlamında yazılan bir yazı için bkz., Gökçen Ertuğrul, “İmkan Olarak Görsel Şiir: Başlangıç Düşünceleri," Yasakmeyve 28 (2007): 35-41. 
$30<$ ilef dergisi 